\title{
Flaxseed Lignan Increased Glucose Uptake by Human Red Blood Cells
}

\author{
Yeong Rhee* and Ardith Brunt
}

351 EML, NDSU Dept. \# 2620, PO Box 6050, North Dakota State University, Fargo, ND, 58108-6050; Department of
Health, Nutrition and Exercise Sciences, North Dakota State University, Fargo, North Dakota

\begin{abstract}
The objective of this study was to determine if flaxseed lignan (secoisolariciresinol diglucoside, SDG) would improve glucose uptake by human red blood cells (RBCs). To measure glucose uptake of RBCs, the RBCs were pretreated, in vitro, with SDG $(0,10,50$, or $100 \mu \mathrm{M})$ and then were incubated with or without insulin $(100 \mu \mathrm{U} / \mathrm{ml})$. After incubation, 3-O- $\left({ }^{3} \mathrm{H}-\mathrm{Methyl}\right)-\mathrm{D}$-glucose uptake by the RBCs was measured. RBCs pretreated with 50 or $100 \mu \mathrm{M}$ SDG showed an increase in glucose uptake compared to control $(0 \mu \mathrm{M} \mathrm{SDG})$ or RBCs pretreated with $10 \mu \mathrm{M}$ SDG $(p<0.0001)$. In addition, glucose uptake was increased in RBCs with insulin stimulation compared to RBCs without insulin stimulation $(p<0.0001)$. An interaction between SDG and insulin was also observed $(p<0.0001)$. Pretreatment of RBCs with SDG $(50$ or $100 \mu \mathrm{M})$ and insulin increased glucose uptake compared to those without insulin stimulation $(p<0.0001)$. The results indicate potential beneficial effects of SDG on glycemic control by increasing glucose uptake of RBCs.
\end{abstract}

Key Words: Glucose uptake, flaxseed lignan, SDG, antioxidant.

\section{INTRODUCTION}

Maintaining glucose homeostasis is important in chronic disease prevention. Many studies have found that hyperglycemia increases reactive oxygen species (ROS), thus leading to increased oxidative stress and oxidative damage as indicated by lipid peroxidation or oxidative DNA damage in humans and animals [1-4]. Increased oxidative damage to the cells may lead to chronic disease development such as diabetes and cardiovascular diseases $[5,6]$.

Glucose transport into cells is one of the major mechanisms of glucose homeostasis regulation. Human erythrocytes are readily accessible compared to other tissues, so these cells are used in studying glucose homeostasis [7-9]. Erythrocytes are also a good cell model for studying oxidative stress induced damage [4]. Antioxidant pretreatment of erythrocytes decreased oxidative damage by reducing lipid peroxidation of the membrane [10]. In addition, antioxidant pretreatment protected red blood cells (RBCs) from structural and membrane lipid composition changes which caused by oxidative stress. The protection of RBCs from structural and membrane lipid composition changes maintains the integrity of glucose transporter on RBC membrane, thus maintaining normal glucose uptake by RBCs and contributing to glucose homeostasis [7-9].

Antioxidants such as resveratrol, alpha-lipoic acid, or alpha-tocopherol supplementation or pretreatment of cells with an antioxidant significantly decreased blood glucose concentration and increased glucose uptake by erythrocytes, hepatocytes, adipocytes, and skeletal muscles in animals

*Address correspondence to this author at the 351 EML, NDSU Dept. \# 2620, PO Box 6050, North Dakota State University, Fargo, ND, 581086050; Department of Health, Nutrition and Exercise Sciences, North Dakota State University, Fargo, North Dakota; Tel: 701-231-7476; Fax: 701-2317453; E-mail: yeong.rhee@ndsu.edu
[11-15]. Secoisolariciresinol diglucoside (SDG), a known antioxidant, is found in flaxseed [16-19]. Many studies have found the beneficial effects of SDG supplementation on glycemic control in animals due to decreased oxidative stress and increased antioxidant status $[6,16,18]$. SDG inhibited in vitro DNA scissions and linoleic acid peroxidation which indicate antioxidant activity of SDG [20]. SDG supplementation was associated with decreased serum or pancreatic malondialdehyde (MDA) and ROS in white blood cells, which are used as indicators of oxidative stress in the body $[6,18]$. Comparisons of antioxidant activity of SDG to that of vitamin $\mathrm{E}$ showed better antioxidant activities in SDG [19].

In our lab, hypoglycemic effect of flaxseed supplementation was found in impaired glucose tolerant people [21]. Twelve weeks of flaxseed supplementation decreased average fasting serum glucose concentrations by $16 \%$ while wheat bran supplementation did not change fasting serum glucose concentrations [21]. The current study was conducted as the first step to determine the mechanism of the hypoglycemic effects of flaxseed. Since the glucose lowering effects in the previous study were attributed to the antioxidant in flaxseed, the current study used purified flaxseed SDG. This study was to determine if flaxseed lignan, SDG, would improve in vitro glucose uptake by human red blood cells.

\section{MATERIALS AND METHODOLOGY}

The research protocol was approved by the Institutional Review Board at North Dakota State University.

\section{Reagents}

Purified flaxseed SDG was from Chromadex Co. (Santa Ana, CA); Solvable ${ }^{\mathrm{TM}}$ was from PerkinElmer (Shelton, CT); $30 \%$ hydrogen peroxide was from VWR (Batavia, IL); scintillation cocktail was from Research Product International 
Co. (Mount Prospect, IL); and the remainders of the reagents were from Sigma Co. (St. Louis, MO).

\section{RBC Isolation}

Heparinized human blood was centrifuged to remove the plasma, and then the red blood cell (RBC) pellet was washed with phosphate-buffered saline (PBS). Then the RBC pellet was re-suspended at the original blood volume with PBS.

\section{SDG Pretreated RBC}

SDG was dissolved in $0.1 \%$ ethanol and diluted into 10 $\mu \mathrm{M}, 50 \mu \mathrm{M}$, or $100 \mu \mathrm{M}$. One $\mathrm{ml}$ of $10 \mu \mathrm{M}, 50 \mu \mathrm{M}$, or 100 $\mu \mathrm{M}$ SDG or $0.1 \%$ ethanol solution ( $0 \mu \mathrm{M}$ SDG, control) was added to $2 \mathrm{ml}$ of the $\mathrm{RBC}$ suspension, and incubated in a dark and sealed system at $37^{\circ} \mathrm{C}$ for 1 hour. After incubation, the RBCs were washed with PBS and then re-suspended in PBS at the original blood volume.

\section{RBC Incubation with Insulin}

Porcine insulin was dissolved in $1 \mathrm{M} \mathrm{HCl}$ and then diluted into $100 \mu \mathrm{U} / \mathrm{ml}$ with PBS. One $\mathrm{ml}$ of $100 \mu \mathrm{U} / \mathrm{ml}$ insulin or $1 \mathrm{M} \mathrm{HCl} / \mathrm{PBS}$ (control) was added to $1 \mathrm{ml}$ of SDG pretreated RBC suspension, and incubated at $37{ }^{\circ} \mathrm{C}$ for 30 minutes. After incubation, the RBCs were washed with PBS, and re-suspended in PBS at the original blood volume. For the glucose uptake assay, $100 \mu \mathrm{l}$ of RBC suspension was transferred into individual tubes.

\section{Preparation of Radiolabeled Solution}

Five $\mathrm{ml}$ of $0.5 \mu \mathrm{Ci} / \mathrm{ml} 3-\mathrm{O}-\left({ }^{3} \mathrm{H}\right.$-Methyl $)-\mathrm{D}$-glucose was mixed with $5 \mathrm{ml}$ of $0.5 \mathrm{mmol} / 1$ 3-O-Methyl-D-glucopyranose (3OMG).

\section{Stop Solution}

Twenty $\mu \mathrm{mol} / 1 \mathrm{mercuric}$ chloride and $10 \mu \mathrm{mol} / \mathrm{l}$ phloretin were added into $100 \mathrm{ml}$ of ice-cold PBS immediately before use.

\section{RBC Glucose Uptake}

RBC glucose uptake was measured using a modified method developed by Klepper et al. [22]. Glucose uptake was initiated by adding $200 \mu \mathrm{l}$ of ${ }^{3} \mathrm{H}$-labeled $3 \mathrm{OMG}$ solution into each $100 \mu \mathrm{l}$ of $\mathrm{RBC}$ suspension which prepared at previous steps. Glucose uptake was stopped by adding $1 \mathrm{ml}$ of ice-cold stop solution at $30 \mathrm{sec}, 1 \mathrm{~min}$, and $25 \mathrm{~min}$. For the control, $1 \mathrm{ml}$ of stop solution was added to $100 \mu \mathrm{l}$ of RBC suspension, and then $200 \mu \mathrm{l}$ of ${ }^{3} \mathrm{H}$-labeled 3OMG solution was added. The RBC suspension was centrifuged at 2,000 $\mathrm{g}$ for $5 \mathrm{~min}$ and then washed twice with $1 \mathrm{ml}$ stop solution. To digest RBC pellet, $250 \mu$ l of Solvable ${ }^{\mathrm{TM}}$ was added, incubated at $60{ }^{\circ} \mathrm{C}$ for $1 \mathrm{hr}$, and then cooled at room temperature. The RBC pellet was further digested by adding $250 \mu \mathrm{l}$ of $30 \%$ hydrogen peroxide and incubated at $60{ }^{\circ} \mathrm{C}$ for 30 minutes. Finally, $4 \mathrm{ml}$ of scintillation cocktail was added to each vial and then counted with a scintillation counter (Beckman Coulter, Inc., Fullerton, CA) for 5 min count per sample.

\section{Data Analysis}

RBC glucose uptake data were analyzed with the SAS System (SAS 9.1; SAS Inst., Cary, NC) using an ANOVA model. The original analysis used an effects model specification which included all main effects and two- and threefactor interactions for the primary factors of interest. A Type I error rate (alpha level) of 0.05 was used for all tests. Follow-up comparisons of means were performed using a cell means model approach which allows comparing means from any treatment combinations rather than just main effects means. The Tukey-Kramer method was used to control the experimentwise error rate for these follow-up tests. Data were reported as mean \pm standard error.

\section{RESULTS}

Hemocytometer counting of the RBC suspension showed an average number of $7.88 \times 10^{6} \mathrm{RBC} / \mu 1$, and also showed a $>95 \%$ of cell viability. There was no time effect on glucose uptake of RBCs. However, the pretreatment of RBCs with either $50 \mu \mathrm{M}$ or $100 \mu \mathrm{M}$ SDG increased glucose uptake compared to RBCs without or with $10 \mu \mathrm{M}$ SDG pretreatment $(p<0.0001$, Fig. 1). No difference was observed in glucose uptake between the $50 \mu \mathrm{M}$ and $100 \mu \mathrm{M}$ SDG groups.

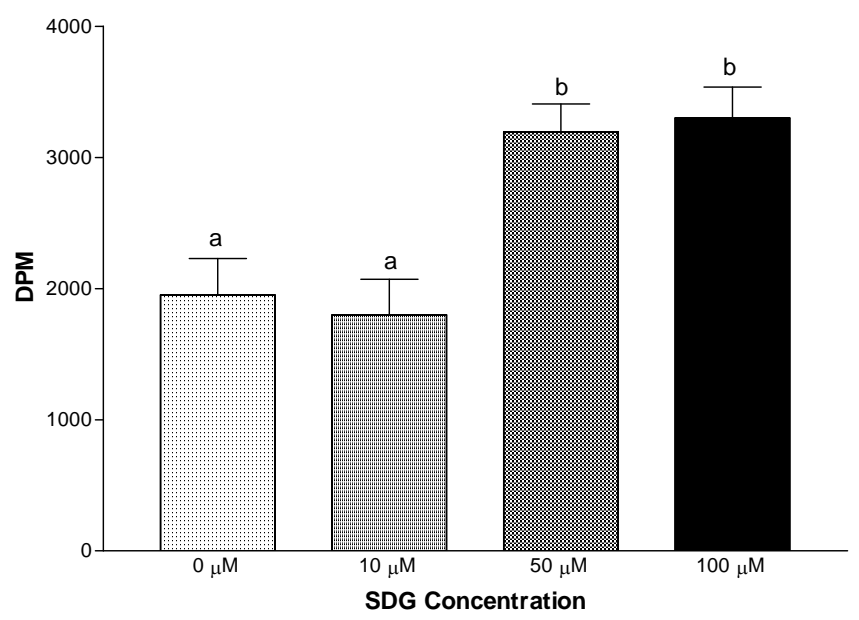

Fig. (1). Effects of SDG on RBC glucose uptake. The data shown are representative of three independent experiments, with the mean and standard error of the mean shown for each treatment group. Since there were no time effects on RBC glucose uptake, the mean of all different times for each treatment group was used for data presentation. Values with different lower case letters are significantly different $(p<$ $0.0001)$. 
RBCs incubated with $100 \mu \mathrm{U} / \mathrm{ml}$ insulin increased glucose uptake compared to RBCs without insulin $(p<0.0001$, Fig. 2). Increased glucose uptake followed by SDG $(50 \mu \mathrm{M}$ or $100 \mu \mathrm{M})$ treatment was also observed in groups without insulin stimulation $(p<0.0001$, Fig. 3). An interaction between SDG and insulin was observed. Pretreatment of RBCs with SDG $(50 \mu \mathrm{M}$ or $100 \mu \mathrm{M})$ and insulin increased glucose uptake compared to those without insulin stimulation $(p<0.0001$, Fig. 3). When comparing an increase of glucose uptake followed by $50 \mu \mathrm{M}$ SDG or 100

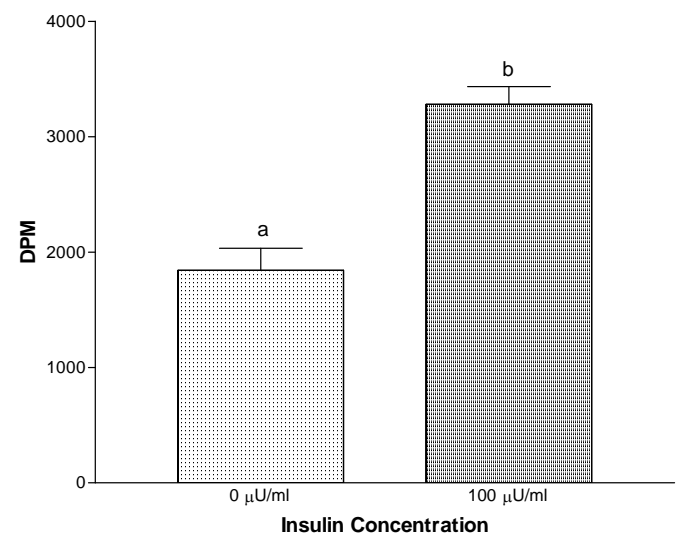

Fig. (2). Effects of insulin on RBC glucose uptake. The data shown are representative of three independent experiments, with the mean and standard error of the mean shown for each treatment group. Since there were no time effects on RBC glucose uptake, the mean of all different times for each treatment group was used for data presentation. Values with different lower case letters are significantly different $(p<0.0001)$. $\mu \mathrm{M}$ SDG without insulin pretreatment to that of cells with $100 \mu \mathrm{U} / \mathrm{ml}$ insulin and SDG $(0 \mu \mathrm{M}$ or $10 \mu \mathrm{M})$ pretreatment, a similar increase of glucose uptake was observed $(p<0.0001$, Fig. 3). However, no interaction between time and SDG or time and insulin was observed.

\section{DISCUSSION AND CONCLUSION}

Generally, the contribution of glucose uptake by erythrocyte to glucose homeostasis is rather small and may not be a major mechanism of the blood glucose lowering effect. However, due to easy accessibility, erythrocytes were used in this study to measure basal glucose uptake as the first step in the identification of the mechanism of glucose lowering effects of flaxseed. Since this study was to measure glucose uptake by RBCs, the antioxidant activity of SDG was not measured in the current study. However, twelve weeks of flaxseed supplementation decreased plasma MDA concentration in glucose intolerant people in our previous study (Unpublished result). This result indicates that SDG in flaxseed functioned as an antioxidant.

Significant improvement of RBC glucose uptake by SDG treatment is in agreement of findings of other studies of antioxidants $[11,12]$. These studies suggested that the protective function of an antioxidant against oxidative stress improved in vitro glucose uptake and led to a decreased insulin resistance in animals $[11,13,23,24]$. Although SDG effects on oxidative stress in RBCs were not determined in the current study, SDG may have acted similarly as other antioxidants used in other studies [23, 24].

High blood glucose levels generate ROS in individuals who have diabetes or impaired glucose tolerance [25-27]. It

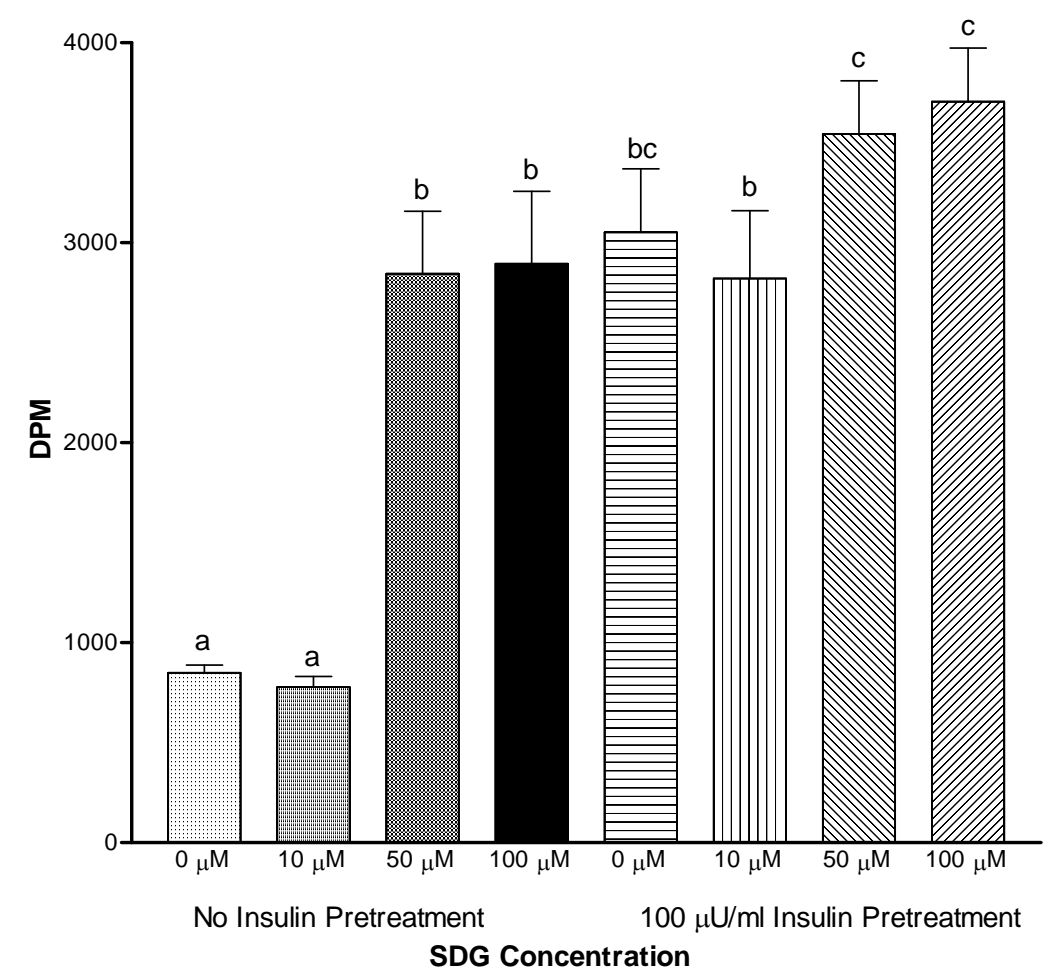

Fig. (3). Effects of SDG and insulin on RBC glucose uptake. The data shown are representative of three independent experiments, with the mean and standard error of the mean shown for each treatment group. Since there were no time effects on RBC glucose uptake, the mean of all different times for each treatment group was used for data presentation. Values with different lower case letters are significantly different $(p<0.0001)$. 
is theorized that glucose in the red blood cell cultures had similar effects on ROS generation. As a result, this generated ROS may have caused a lower glucose uptake by RBCs without SDG treatment. Moreover, increased ROS may have increased membrane lipid peroxidation which disturbed membrane integrity and decreased glucose transporter activation on red blood cells.

Improved glucose uptake by RBCs with SDG pretreatment may be explained by decreased oxidative stress, since SDG functions as an antioxidant. As seen in other studies of antioxidants [9], SDG is an antioxidant which may have decreased lipid peroxidation and oxidative damage on RBCs, thus maintaining the integrity of the cell membranes and cellular structures including glucose transporters. Therefore, decreased lipid peroxidation may have led to increased glucose uptake by RBCs.

Insulin regulates glycemic control by stimulating cellular glucose uptake. RBCs with SDG treatment increased glucose uptake to a similar level as that of insulin stimulated cells. This result indicates that SDG increased basal glucose uptake by RBCs and also SDG has the same or similar hypoglycemic effect as insulin.

Insulin pretreatment of RBCs should not have affected glucose uptake directly, since RBCs transport glucose via non-insulin mediated glucose transporter. However, the interactions between insulin and SDG suggest that SDG potentiates insulin action leading to increased glucose uptake by RBCs.

The significant increase in glucose uptake by RBCs with SDG treatment may explain the blood glucose lowering effects of flaxseed in humans as seen in our previous clinical study [21]. Although there is a report on availability of SDG metabolites, enterodiol and enterolactone, in blood after SDG consumption [28], no studies measured the blood concentration of SDG after normal flaxseed lignan consumption. Therefore, it would be difficult to extrapolate the amount of SDG in the RBC suspension into an amount of SDG needed for a whole human body to exert similar improvement of glucose uptake. However, individuals with an insulin/oral medication regimen for diabetes control would benefit by consuming flaxseed in addition to insulin/oral medication. SDG in flaxseed would reduce the required amount of insulin or oral medication.

These results demonstrate the beneficial effects of SDG on in vitro glucose uptake by human RBCs. However, further investigation is needed to determine the effects of SDG on the mechanism of cellular glucose uptake in humans. For example, the in vitro cellular glucose uptake following SDG metabolite, enterodiol and/or enterolactone stimulation and in vivo cellular glucose uptake following SDG supplementation need to be measured to identify the mechanism of hypoglycemic effects of flaxseed in humans.

\section{ACKNOWLEDGEMENTS}

The authors thank Curt Doetkott for aiding in statistical analyses. This study was funded by Grants from NDSU HD\&E College, Swenson Endowment, and North Dakota EPSCoR. The equipment was funded by Grant from the NRI of the USDA CSREES, grant \#2005-35200-15258. No conflict of interest exists. Both authors contributed to the manuscript writing.

\section{REFERENCES}

[1] Kadiiska MB, Gladen BC, Baird DD, et al. Biomarkers of oxidative stress study II: Are oxidation products of lipids, proteins, and DNA markers of CCL4 poisoning? Free Radic Biol Med 2005; 38 : 698-710.

[2] Kadiiska MB, Gladen BC, Baird DD, et al. Biomarkers of oxidative stress study III. Effects of the nonsteroidal anti-inflammatory agents indomethacin and meclofenamic acid on measurements of oxidative products of lipids in CCL4 poisoning. Free Radic Biol Med 2005; 38: 711-8.

[3] Dincer Y, Akcay T, Alademir Z, Ilkova H. Assessment of DNA base oxidation and glutathione level in patients with type 2 diabetes. Mutat Res 2002; 505: 75-81.

[4] Song F, Jia W, Yao Y, et al. Oxidative stress, antioxidant status and DNA damage in patients with impaired glucose regulation and newly diagnosed type 2 diabetes. Clin Sci (Lond) 2007; 112: 599606.

[5] Ford E, Mokdad A, Giles W, Brown D. The metabolic syndrome and antioxidant concentrations. Findings from the third national health and nutrition examination survey. Diabetes 2003; 52: 234652.

[6] Prasad K. Secoisolariciresinol diglucoside from flaxseed delays the development of type 2 diabetes in Zucker rat. J Lab Clin Med 2001; 138: 32-9.

[7] Hu XJ, Peng F, Zhou HQ, Zhang ZH, Cheng WY, Feng HF. The abnormality of glucose transporter in the erythrocyte membrane of Chinese type 2 diabetic patients. Biochim Biophys Acta 2000; 1466: 306-14.

[8] Garnier M, Attali JR, Valensi P, Delatour-Hanss E, Gaudey F, Koutsouris D. Erythrocyte deformability in diabetes and erythrocyte membrane lipid composition. Metabolism 1990; 39: 794-8.

[9] Szablewski L, Oleszczak B, Mrozikiewicz-Rakowska B, Karnafel W, Grytner-Ziecina B. Deoxy-D-glucose transport into lymphocytes, granulocytes and erythrocytes in patients with type 2 diabetes mellitus. Diabetologia 2007; $7: 245-55$.

[10] Ramkumar KM, Rajaguru P, Latha M, Ananthan R. Effect of Gymnema montanum leaves on red blood cell resistance to oxidative stress in experimental diabetes. Cell Biol Toxicol 2008; 24: 233-41.

[11] Su HC, Hung LM, Chen JK. Resveratrol, a red wine antioxidant, possesses an insulin-like effect in streptozotocin-induced diabetic rats. Am J Physiol Endocrinol Metab 2006; 290: E1339-46.

[12] Haidara MA, Ibrahim IM, Al-Tuwaijri AS, Awadalla SA, Yaseen $\mathrm{H}$. Effect of alpha-tocopherol on glucose uptake and contractility in rat skeletal muscle. Med Sci Monit 2003; 9: BR174-7.

[13] Khamaisi M, Potashnik RM, Tirosh A, et al. Lipoic acid reduces glycemia and increases muscle GLUT4 content in streptozotocindiabetic rats. Metabolism 1997; 46: 763-8.

[14] Guo H, Ling W, Wang Q, Liu C, Hu Y, Xia M. Cyanidin 3-glucoside protects 3T3-L1 adipocytes against $\mathrm{H}_{2} \mathrm{O}_{2}$ - or TNF- $\alpha$ induced insulin resistance by inhibiting c-JUN NH2-terminal kinase activation. Biochem Pharmacol 2008; 75: 1393-1401.

[15] Vuong T, Martineau LC, Ramassamy C, Matar C, Haddad PS. Fermented canadian lowbush blueberry juice stimulates glucose uptake and AMP-activated protein kinase in insulin-sensitive cultured muscle cells and adipocytes. Can J Physiol Pharmacol 2007; 85: 956-65.

[16] Prasad K, Mantha SV, Muir AD, Westcott ND. Protective effect of secoisolariciresinol diglucoside against streptozotocin-induced diabetes and its mechanism. Mol Cell Biochem 2000; 206: 141-9.

[17] Prasad K. Hydroxyl radical-scavenging property of secoisolariciresinol diglucoside (SDG) isolated form flaxseed. Mol Cell Biochem 1997; 168: 117-23.

[18] Prasad K. Oxidative stress as a mechanism of diabetes in diabetic BB prone rats: Effect of secoisolariciresinol diglucoside (SDG). Mol Cell Biochem 2000; 209: 89-96.

[19] Prasad K. Antioxidant activity of secoisolariciresinol diglucosidederived metabolites, secoisolariciresinol, enterodiol, and enterolactone. Int J Angiol 2000; 9: 220-5. 
[20] Kitts DD, Yuan YV, Wijewickreme AN, Thompson LU. Antioxidant activity of the flaxseed lignan secoisolariciresinol diglycoside and its mammalian lignan metabolites enterodiol and enterolactone. Mol Cell Biochem 1999; 202: 91-100.

[21] Rhee Y, Brunt A. Flaxseed supplementation was effective in lowering serum glucose and triacylglycerol in glucose intolerant people. JAMA 2006; 9: 28-34.

[22] Klepper J, Garcia-Alvarez M, O'Driscoll KR, et al. Erythrocyte 3-O-methyl-D-glucose uptake assay for diagnosis of glucosetransporter-protein syndrome. J Clin Lab Anal 1999; 13: 116-121.

[23] Estrada DE, Ewart HS, Tsakiridis T, et al. Stimulation of glucose uptake by the natural coenzyme alpha-lipoic acid/thioctic acid: Participation of elements of the insulin signaling pathway. Diabetes 1996; 45, 1798-1804.

[24] Yaworsky K, Somwar R, Ramlal T, Tritschler HJ, Klip A. Engagement of the insulin-sensitive pathway in the stimulation of glucose transport by alpha-lipoic acid in 3T3-L1 adipocytes. Diabetologia 2000; 43: 294-303.

[25] Hunt JV, Smith CC, Wolff SP. Autoxidative glycosylation and possible involvement of peroxides and free radicals in LDL modification by glucose. Diabetes 1990; 39: 1420-24.

[26] Baynes JW. Role of oxidative stress in development of complications in diabetes. Diabetes 1991; 40: 405-12.

[27] Thompson K, Godin D. Micronutrients and antioxidants in the progression of diabetes. Nutr Res 1995; 15: 1377-1410.

[28] Kuijsten A, Arts IC, Vree TB, Hollman PC. Pharmacokinetics of enterolignans in healthy men and women consuming a single dose of secoisolariciresinol diglucoside. J Nutr 2005; 135: 795-801.

(C) Rhee and Brunt; Licensee Bentham Open.

This is an open access article licensed under the terms of the Creative Commons Attribution Non-Commercial License (http://creativecommons.org/licenses/by$\mathrm{nc} / 3.0 /$ ) which permits unrestricted, non-commercial use, distribution and reproduction in any medium, provided the work is properly cited. 